\title{
Antioxidant Activities of Ficus elastica Leaves Ethanol Extract and Its Compounds
}

\author{
Chrismis Novalinda Ginting ${ }^{1}$, I Nyoman Ehrich Lister ${ }^{1}$, Ermi Girsang ${ }^{1}$, Dewi Riastawati ${ }^{2}$, \\ Hanna Sari Widya Kusuma ${ }^{3}$, Wahyu Widowati ${ }^{4}$ \\ ${ }^{1}$ Faculty of Medicine, Universitas Prima Indonesia, Medan, Indonesia \\ ${ }^{2}$ Faculty of Health and Pharmacy, Universitas Adiwangsa, Jambi, Indonesia \\ ${ }^{3}$ Biomolecular and Biomedical Research Center, Aretha Medika Utama, Bandung, Indonesia \\ ${ }^{4}$ Faculty of Medicine, Maranatha Christian University, Bandung, Indonesia
}

Background: The excessive free radicals condition called oxidative stress can harmful for the body. To prevent and cure it, the antioxidant agents are required. Nowadays, the natural product extracted from plants have been widely used in folk medicine as antioxidant for the treatment of many diseases. Ficus elastica (rubber tree) has some compounds that has several biological activities, i.e., quercitrin, myricitrin, morin, and eleutheroside B. The F. elastica works against the free radicals and can be potential as antioxidant agent. The purpose of this study was to evaluate antioxidant properties of $F$. elastica ethanolic extract (FEE), quercitrin, myricitrin, morin, and eleutheroside $B$.

Materials and Methods: The antioxidant activities of FEE and standard compounds were evaluated by free radical-scavenging activity of 2,2-diphenyl-1-picrylhydrazil (DPPH), hydrogen peroxide $\left(\mathrm{H}_{2} \mathrm{O}_{2}\right), 2$,2'-azinobis-(3-ethylbenzothiazoline- 6-sulfonic acid) (ABTS), and ferric reducing antioxidant power (FRAP) activities using spectrophotometry method.

Results: FEE has the lowest of DPPH scavenging activity $\left(I_{50}=13.82 \mu \mathrm{g} / \mathrm{mL}\right)$ than other compounds. In $A B T S$ scavenging activity, FEE has moderate activity with $\mathrm{IC}_{50}$ value $23.29 \mu \mathrm{g} / \mathrm{mL}$. In FRAP activity, FEE has moderate activity with value 241.58 $\mu \mathrm{M} \mathrm{Fe}(\mathrm{II}) / \mu \mathrm{g}$, while in $\mathrm{H}_{2} \mathrm{O}_{2}$ scavenging activity, FEE also show moderate activity with $\mathrm{IC}_{50}=83.97 \mu \mathrm{g} / \mathrm{mL} \mathrm{compared}$ to other compounds.

Conclusion: In summary, FEE and the pure compounds (quercitrin, myricitrin, morin, and eleutheroside B) have potential as antioxidant agent.

Keywords: free radical, morin, myricitrin, quercitrin, rubber tree, scavenging activities

\section{Introduction}

Reactive oxygen species (ROS) are highly reactive molecules that may leading to tissues damage via several different cellular molecular pathways. ${ }^{1,2}$ The excessive of free radicals or ROS will create imbalances between free radical molecules and antioxidants and may cause implicated in several metabolic diseases that include heart diseases, diabetes mellitus, skin aging, arthritis, cancer, etc. ${ }^{3}$ Indeed, such mechanisms could receive substantial relief by

Date of submission: April 15, 2019

Last Revised: May 29, 2019

Accepted for publication: May 29, 2019

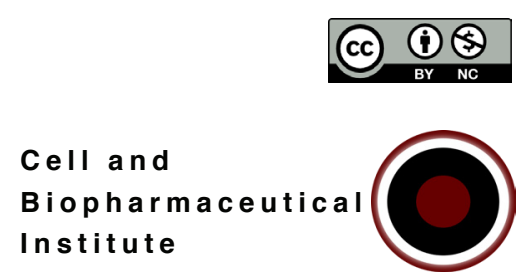


antioxidants. Antioxidants are widely used as ingredients in dietary supplements for health body. The low levels of antioxidants or inhibition of the antioxidant enzymes cause oxidative stress which contributed to many human diseases. ${ }^{4}$

The World Health Organization has realization of the importance of natural products as a therapeutic ingredient alternative which would be able affordable to majority of the world population. ${ }^{5}$ In addition, numerous studies have demonstrated the beneficial effects of natural compounds and antioxidants potential in some medicinal plants. ${ }^{6-8}$ Medicinal plants has advantages and can be alternative source of new chemical with potential therapeutic as antioxidant.

Ficus elastica, commonly known as rubber tree, is an important medicinal plant belonging to the Moraceae family. ${ }^{9} F$. elastica plants are has been widely planted throughout $\mathrm{Asia}^{10}$ possesses pharmacological properties such as antioxidant ${ }^{9}$, anti-inflammatory, and anticancer ${ }^{11}$. Ficus species are reported to be very rich in flavonoids, essential oils, anthocyanins tannins and others phenolic constituents. ${ }^{12}$ F. elastica contain compounds such as rutin, luteolin, coumarins, quercitrin, kaempferin, myricitrin, syringin (eleutheroside B), morin. ${ }^{9,13}$ The $F$. elastica leaves extract has antioxidant activity for the treatment of skin infections and skin allergies. ${ }^{9}$ Hence, the present study has aim to determined the medicinal properties of $F$. elastica for their potential as antioxidant due to 2,2-Diphenyl1-picrylhydrazil (DPPH) scavenging activity, hydrogen peroxide $\left(\mathrm{H}_{2} \mathrm{O}_{2}\right)$ scavenging activity, 2,2'-Azinobis-(3ethylbenzothiazoline- 6-sulfonic acid) (ABTS) scavenging activity and ferric reducing antioxidant power assay (FRAP) activity compared to standard compounds (quercitrin, myricetin, morin, and eleutheroside B).

\section{Materials and methods}

\section{Preparation of F. elastica Extract}

The leaves of $F$. elastica L. were obtained from Raya Village, Karo, Sumatera Utara, Indonesia. Samples were identified by taxonomist of School of Life Science and Technology, Institut Teknologi Bandung, Bandung, Indonesia (No. Specimen: 0140718-A017). About $195 \mathrm{~g}$ of dried F. elastica leaves were mashed, and $2400 \mathrm{~mL} 70 \%$ ethanol solvents was used for extraction and every $24 \mathrm{~h}$, the ethanol filtrate were collected until the filtrate became colourless. This maceration method was using evaporator with $50^{\circ} \mathrm{C}$ temperature to obtain extract. As much as 9.42 g of $F$. elastica extract was stored at $-20^{\circ} \mathrm{C} .{ }^{8,14}$ Quercitrin (Catalogue \#BP1192, Chengdu Biopurify Phytochemicals Ltd., Chengdu, China), morin (Catalogue \#BP0959, Chengdu Biopurify Phytochemicals), myricitrin (Catalogue \#BP0971, Chengdu Biopurify Phytochemicals), and eleutheroside B (Catalogue \#BP0525, Chengdu Biopurify Phytochemicals) were used as standard compounds. In this study, all the samples were dissolved in dimethyl sulfoxide (DMSO) 10\% before the used.

\section{DPPH Free Radical Scavenging Assay}

The $50 \mu \mathrm{L}$ of samples (F. elastica extract, quercitrin, myricitrin, morin, and eleutheroside $B$ ) in various concentration $(0.98 ; 1.95 ; 3.91 ; 7.82 ; 15.63 ; 31.26 \mu \mathrm{g} / \mathrm{mL})$ were introduced in a 96-well microplate. Two hundred $\mu \mathrm{L}$ of DPPH solution(Catalogue\#D9132, SigmaAldrich, Missouri, USA) was added and then incubated for $30 \mathrm{~min}$ at a room temperature in the dark room. Moreover, the absorbance at $517 \mathrm{~nm}$ wave length was read using a microplate reader (Multiskan GO Microplate Spectrophotometer, Thermo Scientific, Massachusetts, USA). ${ }^{7,8,15}$ The experiment was carried out in triplicate and DPPH scavenging activity was calculated using the equation:

$\%$ scavenging activity $=\underline{\text { control absorbance }- \text { sample absorbance }} \times 100$ control absorbance

\section{ABTS Scavenging Activity Assay}

ABTS assay of FEE, quercitrin, morin, myricitrin, and eleutheroside $\mathrm{B}$ were conducted based on cited methods with modification. Around $14 \mathrm{mM}$ of ABTS and $4.9 \mathrm{mM}$ of potassium persulfate (Catalogue \#EM105091, Merck, New Jersey, USA) was reacted in dark room, for $16 \mathrm{~h}$ at room temperature. The mixture solution was mixed with 5.5 $\mathrm{mM}$ phospate-buffered saline (PBS) until the absorbance value reached $0.70 \pm 0.02$ at $745 \mathrm{~nm}$ wavelength. Two $\mu \mathrm{L}$ of sample in various concentration $(1.56 ; 3.13 ; 6.25 ; 12.50$; $25.00 ; 50.00 \mu \mathrm{g} / \mathrm{mL}$ ) were added to each well at 96-well microplate, $198 \mu \mathrm{L}$ ABTS solution was added and then incubated at $30^{\circ} \mathrm{C}$, for $6 \mathrm{~min}$. The absorbance was measured at $745 \mathrm{~nm}$ using a microplate reader (Multiskan GO Microplate Spectrophotometer, Thermo Scientific). ${ }^{14-16}$

The analysis was carried out in triplicates. The ABTS reducing activity was calculated with the formula:

\footnotetext{
$\%$ reducing activity $=$ control absorbance - sample absorbance $\mathrm{x} 100$
} control absorbance 


\section{FRAP Asssay}

The FRAP was done using modified method. ${ }^{8,14,16}$ As much as $7.50 \mu \mathrm{L}$ samples with various concentration and $142.50 \mu \mathrm{L}$ of FRAP reagent was introduced into 96well plate. And then incubated for $30 \mathrm{~min}$ at $37^{\circ} \mathrm{C}$. Briefly, the absorbance was measured with a microplate reader (Multiskan GO Microplate Spectrophotometer, Thermo Scientific) at $593 \mathrm{~nm}$.

\section{$\mathrm{H}_{2} \mathrm{O}_{2}$ Scavenging Activity}

Sixty $\mu \mathrm{L}$ of $F$. elastica extract, quercitrin, myricetin, morin, and eleutheroside B was added to 96-well plate and in well blanks. Briefly, $12 \mu \mathrm{L}$ of ferrous ammonium sulfate $(1 \mathrm{mM})$ (Catalogue \#215406, Sigma Aldrich) was added to the well control and sample wells. Sixty-three of DMSO (Catalogue \#1.02952.1000, Supelco, Missouri, USA) was added in the well control and $90 \mu \mathrm{L}$ in the well blank, and $3 \mu \mathrm{L}$ of $\mathrm{H}_{2} \mathrm{O}_{2}(5 \mathrm{mM})$ (Catalogue \#1.08597.1000, Merck) added to the well-sample. Then, $3 \mu \mathrm{L}, 5 \mathrm{mM}$ of $\mathrm{H}_{2} \mathrm{O}_{2}$ were added into 96-well plates, and then incubated for $5 \mathrm{~min}$ at room temperature, in a dark room. The mixture of sample and blank was added 1,10-phenanthroline (Catalogue \#131377, Sigma Aldrich) for around $75 \mu \mathrm{L}$, then incubated again for $10 \mathrm{~min}$ as before. The absorbance value of control and sample also was measured at $510 \mathrm{~nm}$ using a microplate reader. ${ }^{14-16}$ The experiment was carried out in triplicates. The percentage inhibition of $\mathrm{H}_{2} \mathrm{O}_{2}$ scavenging activity using the following equation:

$\%$ scavenging activity $=$ control absorbance - sample absorbance $\times 100$ control absorbance

\section{Results}

\section{DPPH Free Radical Scavenging Activity}

Based on the results, the percetange of DPPH scavenging activity of FEE, quercitrin, morin, myricitrin, and eleutheroside B could be seen in Figure 1. FEE had the lowest activity in the highest concentration $(31.26 \mu \mathrm{g} / \mathrm{mL})$ with value $62.52 \pm 0.66 \%$ compared to other compounds (FEE $<$ eleutheroside $\mathrm{B}<$ morin $<$ quercitrin $<$ myricitrin). Myricitrin had the highest activity with value $96.22 \pm 1.64 \%$. This indicated that FEE has low antioxidant activity through DPPH scavenging activity.

Table 1 showed that the $\mathrm{IC}_{50}$ value of $\mathrm{DPPH}$ scavenging activity of FEE, quercitrin, morin, myricitrin, and eleutheroside $\mathrm{B}$. FEE showed the highest $\mathrm{IC}_{50}$ value $(13.82 \pm 0.51 \mu \mathrm{g} / \mathrm{mL})$ compared to other compounds, this
Table 1. The $\mathrm{IC}_{50}$ of DPPH free radical scavening of FEE, quercitrin, morin, myricitrin, and eleutheroside $B$.

\begin{tabular}{lc}
\hline \multicolumn{1}{c}{ Sample } & $\begin{array}{c}\text { IC }_{\mathbf{5 0}} \text { value } \\
(\boldsymbol{\mu} \mathbf{g} / \mathbf{m L})\end{array}$ \\
\hline FEE & $13.82 \pm 0.51$ \\
Quercitrin & $1.39 \pm 0.16$ \\
Morin & $0.88 \pm 0.51$ \\
Myricitrin & $0.37 \pm 0.45$ \\
Eleutheroside B & $11.01 \pm 0.15$ \\
\hline
\end{tabular}

indicated that FEE has the lowest in DPPH scavenging activity.

\section{ABTS Scavenging Activity}

ABTS scavenging activity of FEE, quercitrin, morin, myricitrin, and eleutheroside B were showed in Figure 2. In Figure 2, FEE has moderate in ABTS scavenging activity (94.46 $\pm 0.56 \%)$ compared to myricitrin $(98.15 \pm 0.14 \%)$, quercitrin $(95.97 \pm 0.66 \%)$, morin $(93.56 \pm 0.63 \%)$, and eleutheroside B $(51.28 \pm 0.95 \%)$.

In Table 2, Morin has the highest ABTS scavenging activity $(8.11 \pm 0.60 \mu \mathrm{g} / \mathrm{mL})$ compared to FEE and other compounds, while FEE had moderate activity $(23.29 \pm 0.07$ $\mu \mathrm{g} / \mathrm{mL}$ ) compared to compounds. However, morin has the highest ABTS scavenging activity compared to FEE and other compounds.

\section{FRAP-reducing Activity}

Figure 3 show FRAP-reducing activity of FEE, quercitrin, morin, myricitrin, and eleutheroside B. FEE show the moderate FRAP-reducing activity compared to eleutheroside $\mathrm{B}$, myricitrin, quercitrin, and morin in the highest concentration $(50.00 \mu \mathrm{g} / \mathrm{mL})(\mathrm{FEE}: 241.58 \pm 0.52$

Table 2. The $\mathrm{IC}_{50}$ of $\mathrm{ABTS}$ reducing activity of $\mathrm{FEE}$, quercitrin, morin, myricitrin, and eleutheroside $B$.

\begin{tabular}{lc}
\hline \multicolumn{1}{c}{ Sample } & $\begin{array}{c}\text { IC }_{\mathbf{5 0}} \text { value } \\
(\boldsymbol{\mu g} / \mathbf{m L})\end{array}$ \\
\hline FEE & $23.29 \pm 0.07$ \\
Quercitrin & $15.48 \pm 0.22$ \\
Morin & $8.11 \pm 0.60$ \\
Myricitrin & $8.26 \pm 0.68$ \\
Eleutheroside B & $46.26 \pm 1.06$ \\
\hline
\end{tabular}




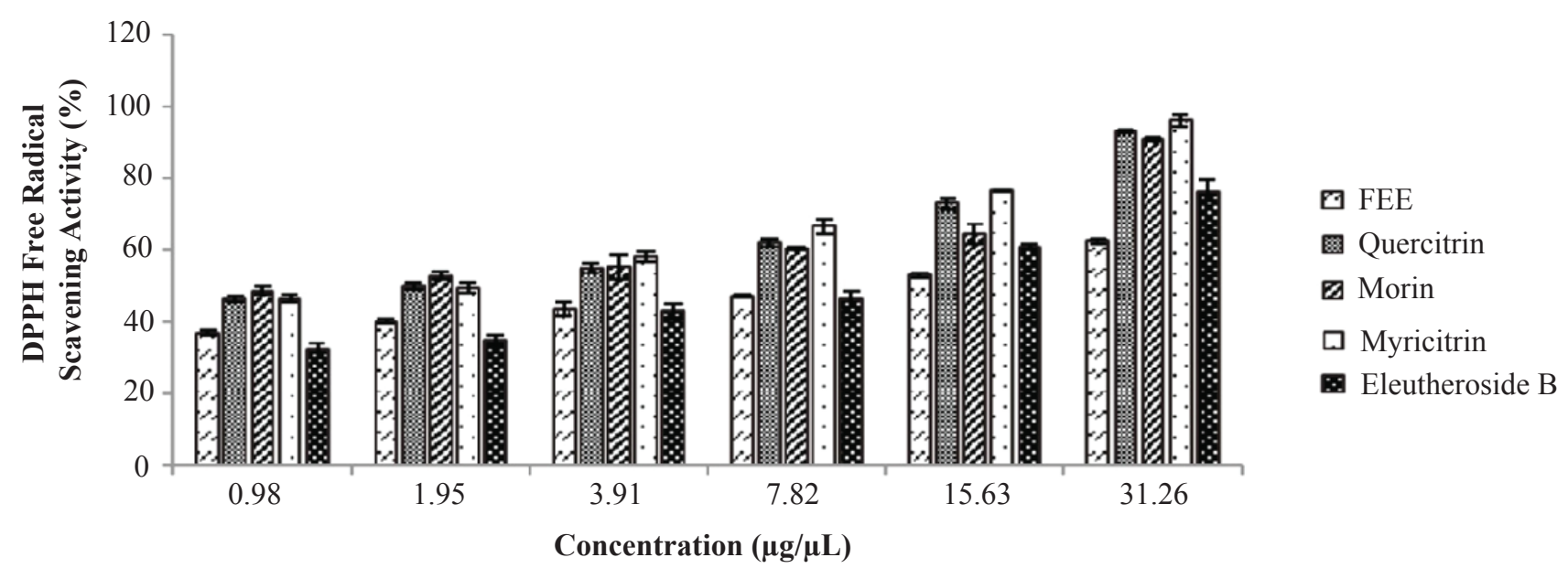

Figure 1. DPPH free radical scavenging activity of FEE, quercitrin, morin, myricitrin, and eleutheroside B. FEE, quercitrin, morin, myricitrin and eleutheroside B were diluted in DMSO 10\% to reach the final concentration of $0.98 ; 1.95$; $3.91 ; 7.82 ; 15.63 ; 31.26 \mu \mathrm{g} / \mu \mathrm{L}$.

$\mu \mathrm{M} \mathrm{Fe}(\mathrm{II}) / \mu \mathrm{g}$, eleutheroside B: $117.08 \pm 27.35 \mu \mathrm{M} \mathrm{Fe}(\mathrm{II}) /$ $\mu \mathrm{g}$, myricitrin: $456.00 \pm 13.43 \mu \mathrm{M} \mathrm{Fe}(\mathrm{II}) / \mu \mathrm{g}$, quercitrin: $487.58 \pm 5.59 \mu \mathrm{M} \mathrm{Fe}(\mathrm{II}) / \mu \mathrm{g}$, morin: $496.58 \pm 9.25 \mu \mathrm{M} \mathrm{Fe}(\mathrm{II}) /$ $\mu \mathrm{g})$. Therefore, FEE has moderate antioxidant activity and not higher compared to morin compound.

\section{$\mathrm{H}_{2} \mathrm{O}_{2}$ Scavenging Activity}

Figure 4 show the $\mathrm{H}_{2} \mathrm{O}_{2}$ scavenging activity of FEE, quercitrin, morin, myricitrin, and eleutheroside B. FEE show moderate of $\mathrm{H}_{2} \mathrm{O}_{2}$ scavenging activity compared to the others in the highest concentration $125.00 \mu \mathrm{g} / \mathrm{mL}$ (FEE: $61.55 \pm 2.84 \%$, eleutheroside B: $38.49 \pm 0.27 \%$, quercitrin: $61.32 \pm 0.16 \%$, morin: $64.92 \pm 1.45 \%$, and myricitrin: $75.07 \pm 3.96 \%$. That indicated FEE has antioxidant activity but not higher than myricitrin.

As shown in Table 3, FEE show the moderate value $(83.97 \pm 2.23 \mu \mathrm{g} / \mathrm{mL})$ compared to eleutheroside $\mathrm{B}$, morin, myricitrin, and quercitrin. That show FEE has moderate antioxidant activity but not higher than quercitrin $(49.11 \pm 5.12 \mu \mathrm{g} / \mathrm{mL})$.

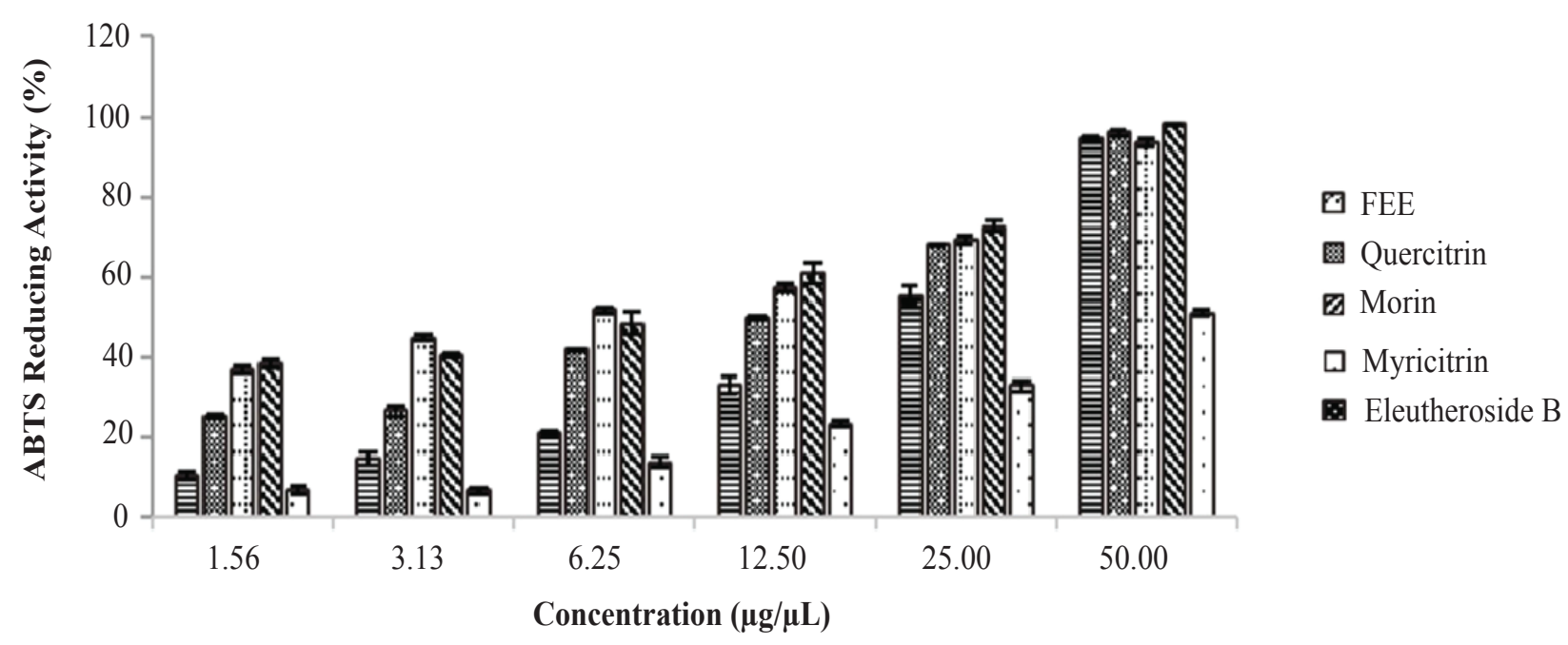

Figure 2. AABTS reducing activity of FEE, quercitrin, morin, myricitrin, and eleutheroside B. FEE, quercitrin, morin, myricitrin, and eleutheroside B were diluted in DMSO $10 \%$ to reach the final concentration of $1.56 ; 3.13 ; 6.25 ; 12.50 ; 25.00$; $50.00 \mu \mathrm{g} / \mu \mathrm{L}$. 


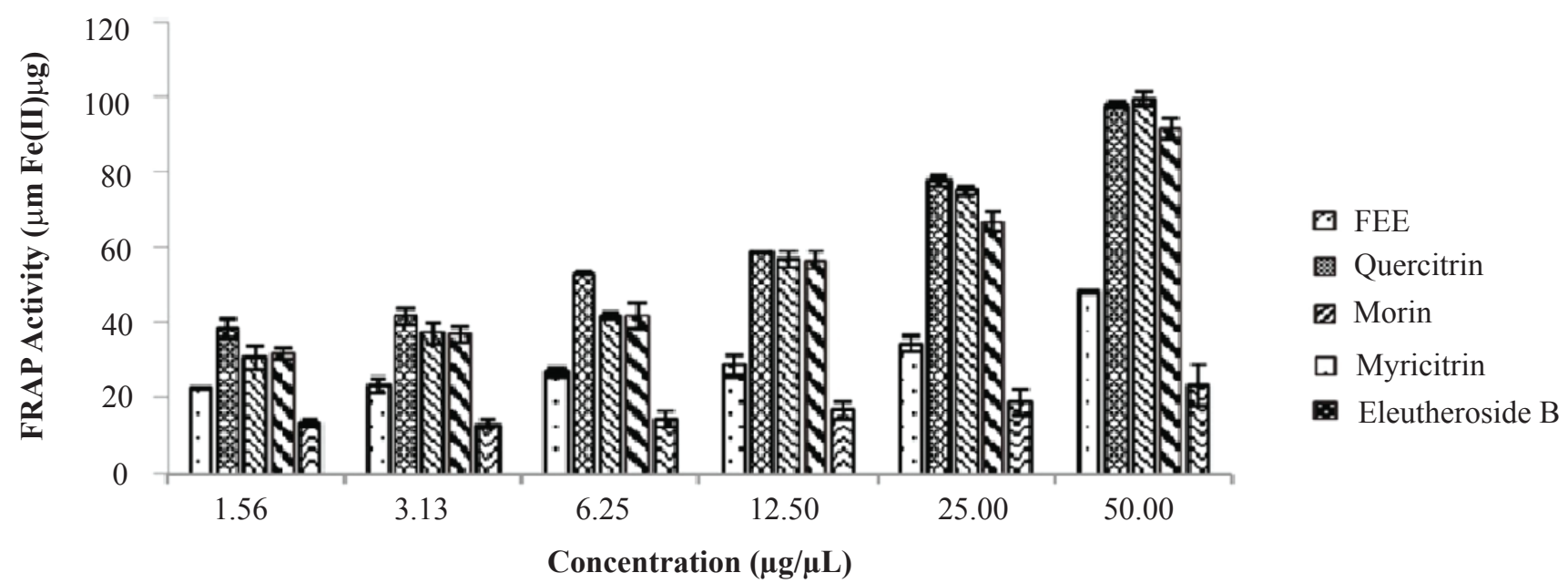

Figure 3. FRAP activity of FEE, quercitrin, morin, myricitrin, and eleutheroside B. FEE, quercitrin, morin, myricitrin, and eleutheroside B were diluted in DMSO $10 \%$ to reach the final concentration of $1.56 ; 3.13 ; 6.25 ; 12.50 ; 25.00$; $50.00 \mu \mathrm{g} / \mu \mathrm{L}$.

\section{Discussion}

F. elastica from Moraceae family has been known as antioxidant properties. Ficus leaves has the highest amount of bioactive compound compared to peels and pulp. ${ }^{17}$ F. elastica has many compounds such as rutin, luteolin, coumarins, quercitrin, kaempferin, myricitrin, syringin (eleutheroside B), and morin. ${ }^{9,13}$ Based on phytochemical analysis, the methabolic extract of $F$. elastica leaves showed the presence of carbohydrates, tannins, phytosterols, phenolics, and flavonoids. F. elastica extract also has high quantity of total phenolic and flavonoid with each value $64.005 \mathrm{mg}$ GAE/gm and $43.003 \mathrm{mg}$ QE/gm. ${ }^{18}$ Antioxidant activities of $F$. elastica and its compounds was carried out in this study through $\mathrm{DPPH}, \mathrm{H}_{2} \mathrm{O}_{2}$ radicals scavenging activities, ABTS scavenging activity, FRAP activity. These

Table 3. The $\mathrm{IC}_{50}$ value of $\mathrm{H}_{2} \mathrm{O}_{2}$ scavenging activity of FEE, quercitrin, morin, myricitrin, and eleutheroside $B$.

\begin{tabular}{lc}
\hline \multicolumn{1}{c}{ Sample } & $\begin{array}{c}\text { IC }_{\mathbf{5 0}} \text { value } \\
(\boldsymbol{\mu g} / \mathbf{m L})\end{array}$ \\
\hline FEE & $83.97 \pm 2.23$ \\
Quercitrin & $49.11 \pm 5.12$ \\
Morin & $60.29 \pm 3.62$ \\
Myricitrin & $58.04 \pm 1.84$ \\
Eleutheroside B & $155.47 \pm 1.27$ \\
\hline
\end{tabular}

antioxidant methods are used in this study because has some advantages such as simple, cheap, user friendly, and show the representative data. ${ }^{19}$

Antioxidant activity in the sample was detected by change colour of DPPH to dark purple DPPH after receiving protons from antioxidants and reducing the color of the protonated DPPH molecules to 1,1 diphenyl2-picrylhydrazine which was yellowish or pale yellow. ${ }^{20}$ The leaves methanol extract of some species Ficus has DPPH scavenging activity. ${ }^{21}$ These results indicate that the methanol extracts have scavenging free radicals activities and can be related to the high phenolic compound present. ${ }^{3}$ In the present study, quercitrin has moderate activity while myricitrin has the highest DPPH scavenging activity (Table 1). This result in line with other study which state that quercitrin has moderate antioxidant activity because has $\mathrm{DPPH}$ activity value $65.05 \%$ and has $\mathrm{IC}_{50}$ value 11.17 $\mu \mathrm{M} .{ }^{22}$ In other study, the methanolic extract of $F$. elastica leaves has potent as antioxidant because has the highest in DPPH scavenging activity $\left(\mathrm{IC}_{50}=15.40 \mu \mathrm{g} / \mathrm{mL}\right)$ compared to methanolic extract of $F$. elastica branches $\left(\mathrm{IC}_{50}=26.90\right.$ $\mu \mathrm{g} / \mathrm{mL})^{23}$ Myricitrin or myricetin-3-O-a-rhamnoside is a phenolic compound which exhibited antioxidant activity due to DPPH scavenging activity $\left(\mathrm{IC}_{50}=1.31 \pm 0.19 \mu \mathrm{g} / \mathrm{mL}\right)$ and $\mathrm{H}_{2} \mathrm{O}_{2}$ scavenging activity $\left(\mathrm{IC}_{50}=28.46 \pm 0.67 \mu \mathrm{g} / \mathrm{mL}\right)$ compared to silymarin. ${ }^{24}$

The present study show that morin has the highest in DPPH and ABTS scavenging activities compared to other compounds (Table 1 and 2). The methanol extract 


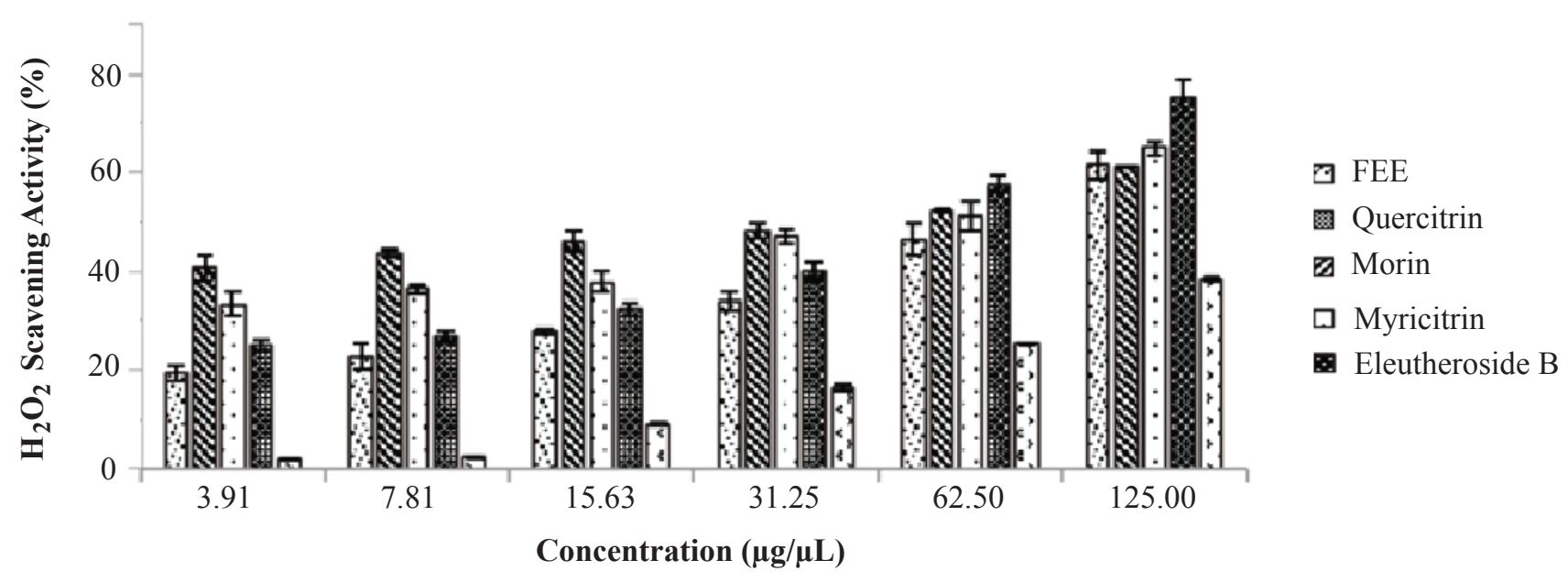

Figure 4. $\mathrm{H}_{2} \mathrm{O}_{2}$ scavenging activity of FEE, quercitrin, morin, myricitrin, and eleutheroside $\mathrm{B}$. FEE, quercitrin, morin, myricitrin, and eleutheroside B were diluted in DMSO $10 \%$ to reach the final concentration of $3.91 ; 7.81 ; 15.63 ; 31.25 ; 62.50$; $125.00 \mu \mathrm{g} / \mu \mathrm{L}$.

from bark, fruits, and leaves F. microcarpa exhibited strong as antioxidant through DPPH and ABTS scavenging activities. ${ }^{17}$ The major phenolic compounds in medicinal plants exhibit stronger antioxidant activity compared to vegetables and fruits. ${ }^{25}$ In other study show that Ficus glomerate also has antioxidant activity due to the presence of flavonoids and phenolics in the extracts. ${ }^{17}$ Morin is a kind of flavonoid compound belonging to the phenolic group which are one of the secondary metabolites of plants and it has antioxidant activity. ${ }^{26}$ Morin is a member flavonols that has ability of reducing oxidative stress and enhancing antioxidant status in hyperammonemic rats. ${ }^{27}$ Flavonoid has antioxidant activity through their redox properties and act as reducing agents, singlet oxygen quenchers, hydrogen donors, and have a metallic chelating potential..$^{25,28}$

In FRAP activity, FEE has moderate activity $(241.58 \pm 0.52 \mu \mathrm{M} \mathrm{Fe}(\mathrm{II}) / \mu \mathrm{g})$ compared other compounds and morin has the highest FRAP activity (Figure 3). This result supported by other study that morin show good antioxidant activity in DPPH scavenging activity with $\mathrm{IC}_{50}$ value $59.00 \mu \mathrm{M}$, and FRAP activity with $\mathrm{IC}_{50}$ value 38.00 $\mu \mathrm{M} .{ }^{29}$ The high total phenolic and flavonoid content in leaf galls of $F$. glomerate methanolic extract may be contributed in ferric reducing power activity. However, the methanolic extract has higher antioxidant potential than aqueous extract. ${ }^{3}$ Number and position of hydroxyl group of phenolic compounds also attributed in their antioxidant activity. ${ }^{3}$

In the present study we using ethanol as solvent of F. elastica extract. The extracts using a high polarity solvent (methanol or ethanol) has more effective as radical scavengers. ${ }^{3}$ Based on the results, quercitrin as flavonoid compound has the highest $\mathrm{H}_{2} \mathrm{O}_{2}$ scavenging activity $\left(\mathrm{IC}_{50}=49.11 \pm 5.12 \mu \mathrm{g} / \mathrm{mL}\right.$ ) (Table 3), it show that the $\mathrm{H}_{2} \mathrm{O}_{2}$ scavenging activity possessed by quercitrin. In other study was reported that quercitrin also has the highest antioxidant activity (Trolox Equivalent) while myricitrin has the highest in antioxidant activity through reducing capacity. ${ }^{9}$ Ficus carica leaves also has antioxidant activity due to the presence of steroids and flavonoids. ${ }^{30}$ However, F. elastica and its compounds can acts as antioxidant agent.

\section{Conclusion}

In this study, we summarize that myricitrin has the highest antioxidant activity through DPPH scavenging activity. In ABTS and $\mathrm{H}_{2} \mathrm{O}_{2}$ scavenging, morin has the highest activities. while quercitrin show the highest antioxidant activity through FRAP activity than $F$. elastica extract.

\section{Acknowledgements}

This study was funded and supported by Universitas Prima Indonesia and Aretha Medika Utama, Biomolecular and Biomedical Research Center, Bandung, Indonesia for a laboratory facilities, and research methodology. We are thankful Ubaydillah Zedd Munshy, Annisa Amalia, Rizal Rizal, Anisa Siwianti, Wahyu Widodo, Ni Luh Wisma Ekayanti, Satrio Haryo Benowo Wibowo, and Maulidwina Bethasari for their valuable assistance. 


\section{References}

1. Birben E, Sahiner UM, Sackesen C, Erzurum S, Kalayci O. Oxidative stress and antioxidant defense. World Allergy Organ J. 2012; 5(1): 1-9. doi: 10.1097/WOX.0b013e3182439613.

2. Widowati W, Noverina R, Ayuningtyas W, Kurniawan D, Faried A, Laksmitawati DR, et al. Reactive oxygen species and aging mechanism. In: Shannon Wilkerson, editor. Reactive Oxygen Species (ROS), Mechanisms and Role in Health and Disease. New York: Nova Science Publishers Inc.; 2018. p.103.

3. Eshwarappa RSB, Iyer S, Subaramaihha SR, Richard SA, Dhananjaya BL. Antioxidant activities of Ficus glomerata (Moraceae) leaf gall extracts. Pharmacognosy Res. 2014; 7(1): 114-20.

4. Nm J, Monika S, Alok S, Alok M, Shruti R. In vitro and in vivo models for antioxidant activity evaluation: a review. Int J Pharm Sci Res. 2010; 1(1): 1-11.

5. David B, Wolfender JL, Dias DA. The pharmaceutical industry and natural products: historical status and new trends. Phytochem Rev. 2015; 14(2): 299-315.

6. Widowati W, Ratnawati H, Husin W, Maesaroh M. Antioxidant properties of spice extracts. Biomed Eng. 2015; 1(1): 24-9.

7. Widowati W, Herlina T, Ratnawati H, Constantia G, Deva IDGS, Maesaroh M. Antioxidant potential of black, green and oolong tea methanol extracts. Biol Med Nat Prod Chem. 2015; 4(2): 35-9.

8. Widowati W, Wargasetia TL, Afifah E, Mozef T, Kusuma HSW, Nufus H, et al. Antioxidant and antidiabetic potential of Curcuma longa and its compounds. Asian J Agric Biol. 2018; 6(2): 149-61.

9. Van Kiem P, Van Minh C, Nhiem NX, Tai BH, Quang TH, Le Tuan Anh $\mathrm{H}$, et al. Chemical constituents of the Ficus elastica leaves and their antioxidant activities. Bull Korean Chem Soc. 2012; 33(10): 3461-4.

10. Chantarasuwan B, Thongsrikem S, Pinyo P, Kanithajata P, Kjellberg F. A natural population of Ficus elastica roxbex hornem. in Thailand. Thail Nat Hist Museum J. 2016; 10(1): 7-14.

11. Ondua M, Njoya EM, Abdalla MA, McGaw LJ. Anti-inflammatory and antioxidant properties of leaf extracts of eleven south african medicinal plants used traditionally to treat inflammation. J Ethnopharmacol. 2019; 234: 27-35.

12. Ahmed F, Urooj A. Traditional uses, medicinal properties, and phytopharmacology of Ficus racemosa: a review. Pharm Biol. 2010; 48(6): 672-81.

13. Khan AS. Medicinally Important Trees. Basel: Springer Nature Switzerland AG; 2017.

14. Widowati W, Afifah E, Herdiman H, Nufus H, Arumwardana S, Rihibiha DD, et al. Antioxidant and anti aging assays of Oryza sativa extracts, vanillin and coumaric acid. J Nat Remedies. 2016; 16(3): 88. doi: 10.18311/jnr/2016/7220.

15. Widowati W, B WJ, Nadya S, Amalia A, Arumwardana S, Kusuma HSW, et al. Antioxidant and antiaging activities of Jasminum sambac extract, and its compounds. J Reports Pharm Sci. 2018; 7(3): 270-85.

16. Widowati W, Rani AP, Hamzah RA, Arumwardana S, Afifah E, Nufus $\mathrm{H}$, et al. Antioxidant and antiaging assays of Hibiscus sabdariffa extract and its compounds. Nat Prod Sci. 2017; 23(3): 192-200.

17. Sirisha N, Sreenivasulu M, Sangeeta K, Madhusudhana Chetty C. Antioxidant properties of Ficus species - a review. Int J PharmTech Res. 2010; 2(4): 2174-82.

18. Yadav P, Jain A, Kumar G, Karthik L, Rao KVB. Phytochemical composition and antioxidant activity of Ficus elastica Roxb. (Moraceae) leaves. Res J Pharm Technol. 2015; 8(3): 259-64.

19. Shalaby EA, Shanab SM. Comparison of DPPH and ABTS assays for determining antioxidant potential of water and methanol extracts of Spirulina platensis. Indian J Geo-Marine Sci. 2013; 42(5): 556-64.

20. Widowati W, Noverina R, Ayuningtyas W, Kurniawan D, Rihibiha DD, Rizal R, et al. Reactive oxygen species as inducers and inhibitors of cancer. In: Shannon Wilkerson, editor. Reactive Oxygen Species (ROS), Mechanisms and Role in Health and Disease. New York: Nova Science Publishers Inc.; 2018.

21. Abdel-Hameed ESS. Total phenolic contents and free radical scavenging activity of certain Egyptian Ficus species leaf samples. Food Chem. 2009; 114(4): 1271-7.

22. Zhang M, Zhao R, Zhou S, Liu W, Liang Y, Zhao Z, et al. Chemical characterization and evaluation of the antioxidants in chaenomeles fruits by an improved HPLC-TOF/MS coupled to an on-line DPPH-HPLC method. J Environ Sci Heal-Part C Environ Carcinog Ecotoxicol Rev. 2018; 36(1): 43-62.

23. El-Hawary SS, Wassel GM, El-Menshawi BS, Ibrahim NA, Mahmoud K, Ayoub MM. Antitumor and antioxidant activity of Ficus elastica Roxb. and icus bengalensis Linn. family Moraceae. World Appl Sci J. 2012; 19(11): 1532-39.

24. Domitrović R, Rashed K, Cvijanović O, Vladimir-Knežević S, Škoda M, Višnić A. Myricitrin exhibits antioxidant, anti-inflammatory and antifibrotic activity in carbon tetrachloride-intoxicated mice. Chem Biol Interact. 2015; 230: 21-9.

25. Hannachi H, Tlili N, Yahia Y, Khaldi A, Nasri N, Ferchichi A, et al. Screening of natural antioxidants from selected medicinal plants. Int J Food Prop. 2012; 16(5): 1117-26.

26. Zuraida Z, Sulistiyani S, Sajuthi D, Suparto IH. Fenol, flavonoid, dan aktivitas antioksidan pada ekstrak kulit batang pulai (Alstonia scholaris R.Br). J Penelit Has Hutan. 2017; 35(3): 211-19.

27. Subash S, Subramanian P. Morin a flavonoid exerts antioxidant potential in chronic hyperammonemic rats: a biochemical and histopathological study. Mol Cell Biochem. 2009; 327(1-2): 15361.

28. Djeridane A, Yousfi M, Nadjemi B, Boutassouna D, Stocker P, Vidal N. Antioxidant activity of some algerian medicinal plants extracts containing phenolic compounds. Food Chem. 2006; 97(4): 654-60.

29. Sinha K, Sadhukhan P, Saha S, Pal PB, Sil PC. Morin protects gastric mucosa from nonsteroidal anti-inflammatory drug, indomethacin induced inflammatory damage and apoptosis by modulating NF- $\mathrm{kB}$ pathway. Biochim Biophys Acta - Gen Subj. 2015; 1850(4): 769-83.

30. Ali B, Mujeeb M, Aeri V, Mir SR, Faiyazuddin M, Shakeel F. Antiinflammatory and antioxidant activity of Ficus carica Linn. Leaves. Nat Prod Res. 2011;26(5):460-65. 